\title{
ÁREAS DE PRESERVAÇÃO PERMANENTE, USOS CONFLITANTES E COBERTURA VEGETAL: UM ESTUDO COMPARATIVO NA BACIA DO RIO BELÉM, CURITIBA - PR
}

\section{AREAS OF PERMANENT PRESERVATION, CONFLICTING USES AND VEGETABLE COVERAGE: A COMPARATIVE STUDY IN THE RIO BELÉM, CURITIBA - PR}

\section{Gustavo Yuri Mine Misael} Universidade Federal do Paraná, Curitiba - PR, discente de mestrado e professor das Faculdades Integradas Camões, Curso de Gestão Ambiental. E-mail: gustavoyuri_misael@yahoo.com.br

\section{RESUMO}

A bacia do rio Belém, situada de norte a sul dentro dos limites do município de Curitiba, apresenta muitos problemas quanto às áreas de preservação permanente (APPs), devido a ocupações desordenadas e irregulares, supressão da vegetação nativa e poluição de suas águas. A pesquisa consistiu em avaliar e comparar duas áreas na bacia do rio Belém, uma na região norte do município de Curitiba e outra na região sul, quanto à conservação das APPs, com base no Novo Código Florestal Brasileiro, bem como analisar os principais conflitos existentes e a taxa de cobertura vegetal das áreas. Para classificar o grau de conservação, adotou-se o método empregado por Moura (2007), quanto à conservação mínima, máxima ou parcial. Foram utilizadas imagens de satélite do Google Earth Pro, bem como software ArcGis 10 para a elaboração de mapas temáticos. Como resultados, foram obtidos mapas temáticos da localização das áreas de Estudo na bacia do rio Belém e mapas apresentando o índice de cobertura vegetal em cada área. Concluiu-se que ambas as áreas não estão de acordo com o Código Florestal, e apresentam graves problemas relacionados aos usos do solo e poluição das águas. Porém, apresentam resultados bem distintos, quanto aos conflitos e conservação da cobertura vegetal.

Palavras-chave: Novo Código Florestal. Usos do solo. Conservação. Conflitos. Vegetação.

\begin{abstract}
The watershed of the Belém river, located of north to south inside of the limits of the municipal district of Curitiba, it presents many problems as for the Areas of Permanent (APPs) Preservation, due to disordered occupations and irregular, suppression of the native vegetation and pollution of their waters. The research consisted of to evaluate and to compare two areas in the watershed of the Belém river, one in the north area of the municipal district of Curitiba and other in the south area, as the conservation of APPs, with base in the New Brazilian Forest Code, as well as to analyze the main existent conflicts and the tax of vegetable covering of the areas. To classify the conservation degree, the method was adopted used by Moura (2007), as for the minimum conservation, maxim or partially. It was used images of satellite of Google Earth Pro, as well as software ArcGis 10 for elaboration of thematic maps. As results were obtained thematic maps of the location of the areas of Study in Rio Belém's watershed and maps presenting the index of vegetable covering in each area. It was ended that both areas are not in agreement with the Forest Code, and they present serious problems related to the uses of the soil and pollution of the waters. However, they present
\end{abstract}


Revista Tecnologia e Ambiente, v. 24, 2018, Criciúma, Santa Catarina/SC ISSN Eletrônico 2358-9426 e ISSN Impresso 1413-8131

very different results, as for the conflicts and conservation of the vegetable covering.

Keywords: New Forest Code. Uses of the Soil. Conservation. Conflicts. Vegetation. 


\section{INTRODUÇÃO}

O crescimento rápido das cidades, o grande aumento populacional e a falta de planejamento urbano aliados a uma falta de consciência ambiental trazem à população alguns problemas ambientais decorrentes dessa aglomeração desordenada. Problemas esses que afetam todo o ecossistema local, a qualidade do ar, da água e do solo, e, consequentemente, a qualidade de vida da população sob vários aspectos.

A presença de cobertura vegetal nas áreas urbanas pode amenizar essa problemática que se torna não só de ordem ambiental, como também social e de saúde pública. A presença de vegetação ajuda a regular o microclima local e ameniza os problemas de impermeabilização de solo, contribuindo para amenizar as enchentes. Além disso, equilibra a biodiversidade local, ajudando a preservar espécies da fauna e da flora, protege a qualidade das águas dos rios e das nascentes e filtra os gases emitidos pelas fontes pontuais e difusas de emissões de gases para a atmosfera, assim como proporciona sombra e beleza paisagística.

Conforme Nucci,

um atributo muito importante, porém negligenciado no desenvolvimento das cidades, é a cobertura vegetal, pois além de todas as necessidades que o ser humano tem em relação à vegetação é importante lembrar que as cidades estão cada vez mais poluídas, e esta poluição, principalmente no ar e nos rios, pode ser reduzida substancialmente preservando-se a vegetação local (2001, p. 23).

A qualidade dos corpos d'água é comprometida principalmente onde há a ausência dessa vegetação, facilitando processos erosivos, contaminação da água por resíduos e carreamento de substâncias poluidoras para os rios.

Nucci e Cavalheiro (1999) definem cobertura vegetal como qualquer área provida de vegetação dentro do espaço urbano, compreendendo a vegetação herbácea, arbustiva e arbórea. Os jardins, os quintais, as praças, os parques, os canteiros em vias de circulação, as áreas preservadas, dentre outras formas de cobertura vegetal, estão compreendidas dentro dessa categoria. Essas áreas podem estar situadas tanto em terrenos públicos quanto em terrenos privados.

Ao se tratar de áreas verdes e da cobertura vegetal nas bacias hidrográficas, um dos fatores principais a se considerar é o estado das APPs (áreas de preservação permanente), onde se devem preservar ou recuperar a vegetação das margens de rios e reservatórios de água, em topos de morros, nas encostas, nas nascentes, entre outros.

De acordo com a legislação florestal, as áreas de preservação permanente são áreas nas quais, por imposição da lei, a vegetação deve ser mantida intacta, tendo em vista garantir a 
preservação dos recursos hídricos, da estabilidade geológica e da biodiversidade, bem como o bem-estar das pessoas (BRASIL, 2012).

Machado (2002) afirma que nessas florestas estão o dever de proteger os cursosd'água, evitar o assoreamento dos rios e as enchentes e fixar as montanhas, evitando-se o frequente soterramento de pessoas nos grandes centros urbanos.

De acordo com Mota (2003), a ocupação de um ambiente natural, no processo de urbanização, geralmente ocorre com a remoção da cobertura vegetal. O desmatamento resulta em vários impactos ambientais, tais como: modificações climáticas; danos à flora e fauna; descobrimento do solo, causando o incremento da erosão; remoção da camada fértil do solo, empobrecendo-o; assoreamento dos recursos hídricos; aumento do escoamento superficial da água e redução da infiltração; e inundações.

Ainda de acordo com Mota (2003), através de vários instrumentos - Disciplinamento do Uso e Ocupação do Solo, Controle do Parcelamento do Solo, Sistema Viário, entre outros, o planejamento urbano deve proporcionar a utilização dos recursos ambientais disponíveis, de forma racional, de modo que eles continuem em condições de uso para todas as gerações.

Em Curitiba, há um elevado índice de áreas verdes por habitante $\left(64,5 \mathrm{~m}^{2} / \mathrm{Hab}\right.$.), o que a torna uma das cidades bem mais arborizadas do Brasil e da América Latina (ONU, 2008). Porém, existem regiões no município, em que a cobertura vegetal praticamente desaparece, por exemplo, nas áreas de ocupações desordenadas e irregulares ao longo dos rios, acarretando sérios problemas de ordem ambiental, social e de saúde pública (IPPUC,2009).

A situação atual da bacia hidrográfica do rio Belém, em termos ambientais, tornou-se preocupante e, ao mesmo tempo, desafiadora. É a bacia que passa pelos bairros de maior densidade de Curitiba (IPPUC, 2005) e corta a área urbana da cidade de norte a sul.

A presente pesquisa teve como objetivo avaliar e comparar o estado de conservação de APPs em dois trechos ao longo do curso do rio Belém. A justificativa para a realização deste estudo se dá diante do problema quanto à presença ou à ausência de cobertura vegetal nas APPs e à adequação quanto ao Novo Código Florestal (2012) vigente, sem envolver as legislações municipais ao longo do rio Belém, bem como seu estado de preservação.

Poucas pesquisas se tem encontrado com relação a essa temática na bacia do rio Belém, e pretende-se, assim, com este estudo, produzir conhecimento através de obtenção de dados, vivência e análise em campo, desenvolvendo uma pesquisa de caráter qualiquantitativa, buscando despertar na sociedade civil maiores atenções a essa temática, podendo 
servir de subsídios a um melhor planejamento urbano e ambiental igualitário em toda área urbana de Curitiba ou de outros municípios.

\section{MÉTODO}

\section{CARACTERIZAÇÃO DA BACIA HIDROGRÁFICA DO RIO BELÉM E DAS ÁREAS DE ESTUDO}

Segundo Fendrich,

a Bacia Hidrográfica do Rio Belém está localizada geograficamente desde as nascentes $($ Cota Topográfica $=990,00 \mathrm{~m})$ até a foz $($ Cota Topográfica $=870 \mathrm{~m})$, dentro dos limites geográficos do município de Curitiba, sendo tributário da margem direita do Rio Iguaçu. Seu talvegue principal desenvolve-se segundo a orientação Norte-Sul, cortando regiões de alto grau de densidade populacional como bairros periféricos das Zonas Norte e Sul e a Zona Central da cidade de Curitiba (2002, p. 5).

De acordo com Bollmann,

a bacia do rio Belém possui $84 \mathrm{~km}^{2}$, sua área de drenagem representa cerca de $20 \%$ da área do Município de Curitiba e abriga aproximadamente $50 \%$ de sua população. Engloba os principais bairros da cidade, entre eles o Centro e os principais pontos notáveis naturais e arquitetônicos que tem representado a Cidade de Curitiba, conferindo-lhe uma grande importância simbólica, consideradas as dimensões geográfica, social, econômica e cultural. Por isso, a bacia do rio Belém é considerada de extrema importância para a cidade de Curitiba (2008, p. 443).

A bacia do rio Belém é uma das principais bacias hidrográficas de Curitiba e, por estar totalmente em área urbana, possui sérios problemas ambientais, como supressão da vegetação, ocupações irregulares, canalização de seu leito, lançamentos de alta carga de esgoto sanitários e industriais, acúmulo de resíduos e enchentes.

O mapa da Figura 1 mostra a localização da bacia do rio Belém, dentro dos limites do município de Curitiba, bem como as duas áreas do estudo.

Para a pesquisa, foram selecionados dois recortes espaciais, em um trecho de $500 \mathrm{~m}$ de curso do rio Belém, uma no bairro Abranches, próximo à montante do Parque São Lourenço, no trecho superior da bacia do rio Belém, distante cerca de $2 \mathrm{~km}$ da área das nascentes. Essa é delimitada entre as Ruas José Brussamolim, Rua Sebastião Fávaro (no Nordeste da área), Rua Lídia Klinger e Rua Edgard Simone mais ao sul.

A outra área está localizada entre os bairros Vila Hauer e Guabirotuba, mais ao sul da bacia, sendo delimitada entre as ruas Roberto Hauer (porção norte da área), rua Bartolomeu Lourenço de Gusmão (porção Oeste), rua Rubens Cardoso de Brito (porção leste), e ao sul pela rua José Rietmeyer (bairro Guabirotuba). 
Figura 1 - Mapa de localização da bacia hidrográfica do Rio Belém e as duas áreas de estudo

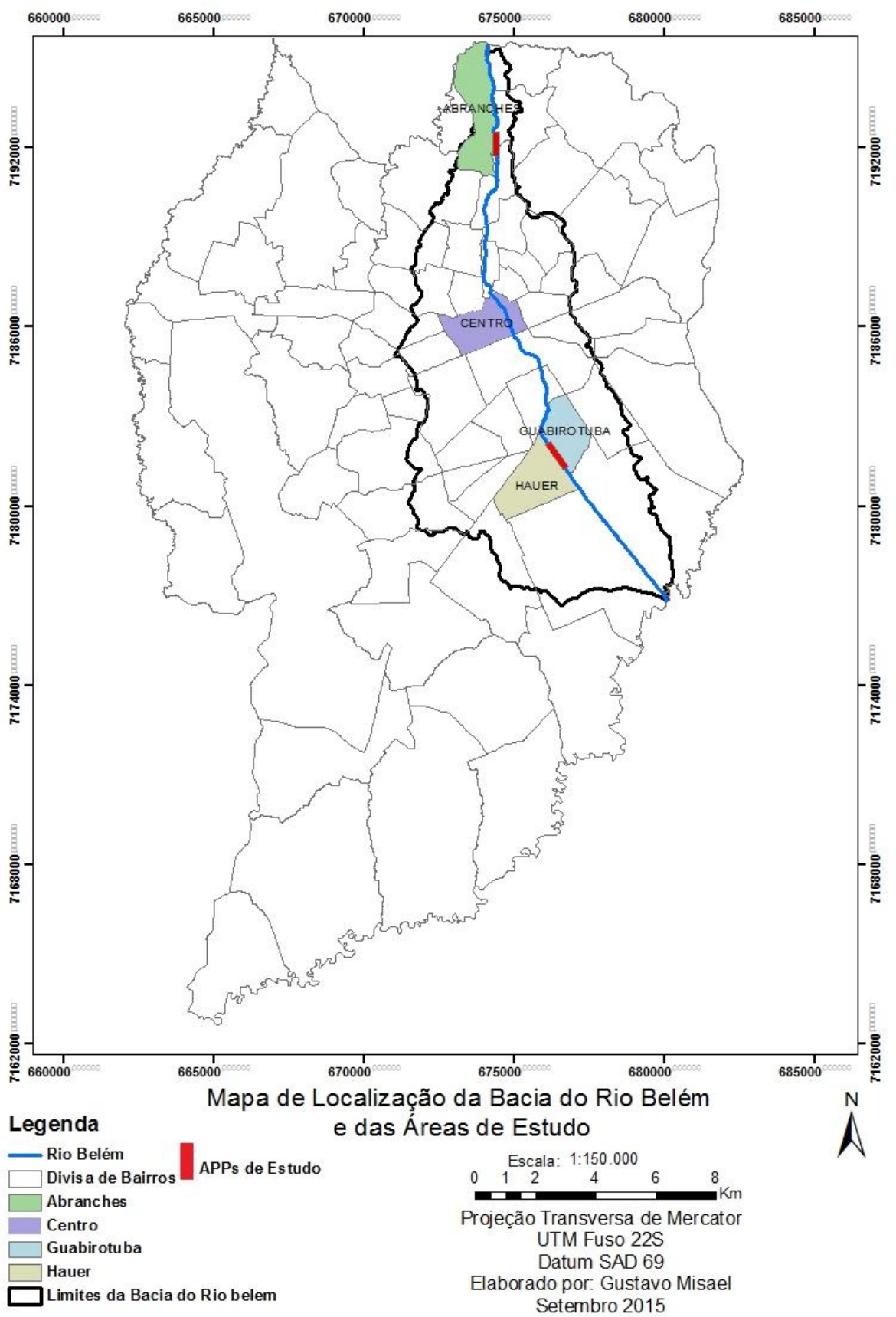

Fonte: Instituto de Terras, Cartografia e Geociências do Paraná, 2016; ArGis 9.3; Misael, 2016.

\section{PROCEDIMENTOS}

Para a análise do enquadramento e delimitação das áreas de APPs, foram adotados os critérios de Preservação Permanente, de acordo com o Novo Código Florestal Brasileiro (2012). 
Para a delimitação das áreas para a análise, foram selecionados, com o auxílio do software Google Earth Pro e sob a imagem de satélite, dois trechos de $500 \mathrm{~m}$ de curso do rio Belém, uma à montante do Parque São Lourenço, no bairro Abranches, abrangendo os Bairros Vila Hauer (margem esquerda) e Guabirotuba (margem direita). Como critério de seleção, baseou-se no perfil do curso do rio Belém e do padrão de ocupação urbana próximos ao curso do rio Belém.

Para a determinação do índice de cobertura vegetal presente na APPs, foi realizado um cálculo de regra de três simples, baseado na área total do recorte espacial de cada área de APP do rio Belém, com a área total de cobertura vegetal obtida pela soma das áreas dos polígonos da cobertura vegetal. Para obter a área da cobertura vegetal, utilizou-se o programa Google Earh Pro para a criação de polígonos sobre a imagem de satélite, bem como o software de geoprocessamento ArcGis versão10. A obtenção do mapa do índice de cobertura vegetal se deu em ambiente do software ArcGis 10, utilizando os polígonos criados para a vegetação, gerando 2 mapas na escala 1:2.500.

Quanto à descrição e quantificação dos conflitos relacionados ao uso e ocupação do solo dentro das APPs, elencaram-se algumas classes relacionados a problemas de ocupação antrópica como: habitação na APP, solo exposto, área com vegetação, contudo sem ser a vegetação original, caminhos e ruas e usos de lazer.

Para caracterizar o grau de conservação das áreas de APPS, adotou-se a classificação elaborada por Moura (2007), conforme o Quadro 1:

Quadro 1 - Grau de conservação das apps e características

\begin{tabular}{|l|l|}
\hline \multicolumn{1}{|c|}{ Grau de Conservação } & \multicolumn{1}{c|}{ Características } \\
\hline Máxima & Ocupada por floresta nativa, e condiz com preservação. \\
\hline Relevante & $\begin{array}{l}\text { Contém vegetação Nativa, seja arbórea, arbustiva ou herbácea em } \\
\text { sua maior parte. }\end{array}$ \\
\hline Parcial & $\begin{array}{l}\text { Vegetação nativa em menor parte da área, possui algum tipo de } \\
\text { ocupação, como urbanização ou uso agrícola (incongruências com a } \\
\text { legislação). }\end{array}$ \\
\hline Mínima & $\begin{array}{l}\text { A urbanização toma conta da maior parte da área, quase sem } \\
\text { resquícios de vegetação. }\end{array}$ \\
\hline
\end{tabular}

Fonte: Moura, 2007. Adaptado pelo autor, 2016.

Para quantificar a área e o percentual dos conflitos nas APPs, utilizou-se mesmo método para quantificar a cobertura vegetal. 


\section{RESULTADOS E DISCUSSÕES}

Constatou-se que ambas APPs não estão de acordo com a legislação ambiental do Novo Código Florestal Brasileiro (2012), além de apresentarem problemas de ocupação do solo dentro da área que deveria ser de preservação permanente, com vegetação contínua. As duas áreas possuem ao entorno do rio Belém diferentes padrões de ocupação do solo, bem como o seu curso se apresenta diferente nesses dois trechos analisados.

No bairro Abranches, o rio Belém possui largura entre 1,5 e $3 \mathrm{~m}$, e sua faixa de preservação, que deveria ter $30 \mathrm{~m}$ em cada margem, não atende ao Novo Código Florestal, e ainda comparado com o trecho na Vila Hauer/Guabirotuba, possui seu curso estreito, não canalizado e menos degradado fisicamente. Já no trecho da Vila Hauer, não acontece o mesmo, visto que se apresenta como um canal retificado e com graves problemas de lançamento de esgotos e de resíduos, ausência de vegetação em alguns trechos e grande adensamento populacional nas margens. Nessa área, o rio Belém possui largura entre 10 e 20 $\mathrm{m}$, e sua faixa de preservação, que deveria ser de $50 \mathrm{~m}$ para cada margem, não atende ao Novo Código Florestal.

\section{COBERTURA VEGETAL}

Do total da área da APP em relação à cobertura vegetal, a área ao norte do parque São Lourenço possui maior índice de cobertura vegetal, 49,61\% (Figura 2), porém essa cobertura vegetal não se enquadra como a vegetação nativa que deveria fazer parte da APP, pois em sua maioria são espécies herbáceas, e a Floresta Ombrófila Mista Aluvial (Floresta nativa) pouco resta nesta área. Entretanto, pode-se considerar a área com estado de Conservação Parcial, por ainda haver pouca área urbanizada dentro da APP, e praticamente metade da área ainda possui cobertura vegetal, mesmo não sendo da vegetação original. Nessa área, a vegetação ciliar se apresenta degradada, com espécies exóticas, como o lírio do brejo, típica de ambientes à beira de corpos-d 'agua.

Já na área mais ao sul da bacia do rio Belém, na Vila Hauer e Guabirotuba, essa possui um índice bem menor de cobertura vegetal, 17,32\% (Figura 3), porém a vegetação se encontra de forma mais contínua (linear) com a presença de espécies herbáceas e pequenos arbustos. 
Figura 2 - Cobertura vegetal na APP na área norte da bacia do Rio Belém.

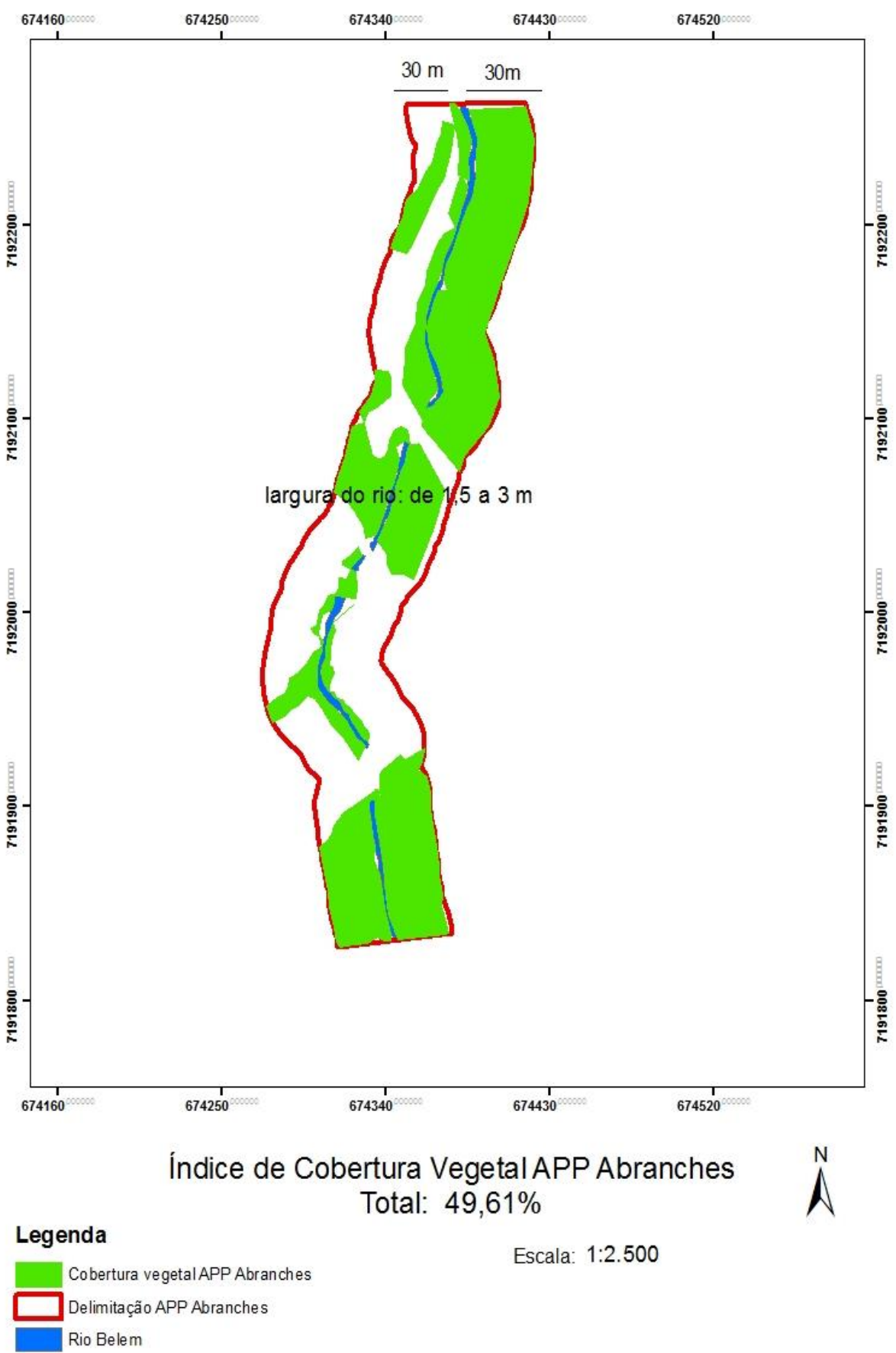

Fonte: Elaborada pelo autor, 2016. 
Figura 3: Cobertura vegetal na APP na área sul da bacia do Rio Belém.

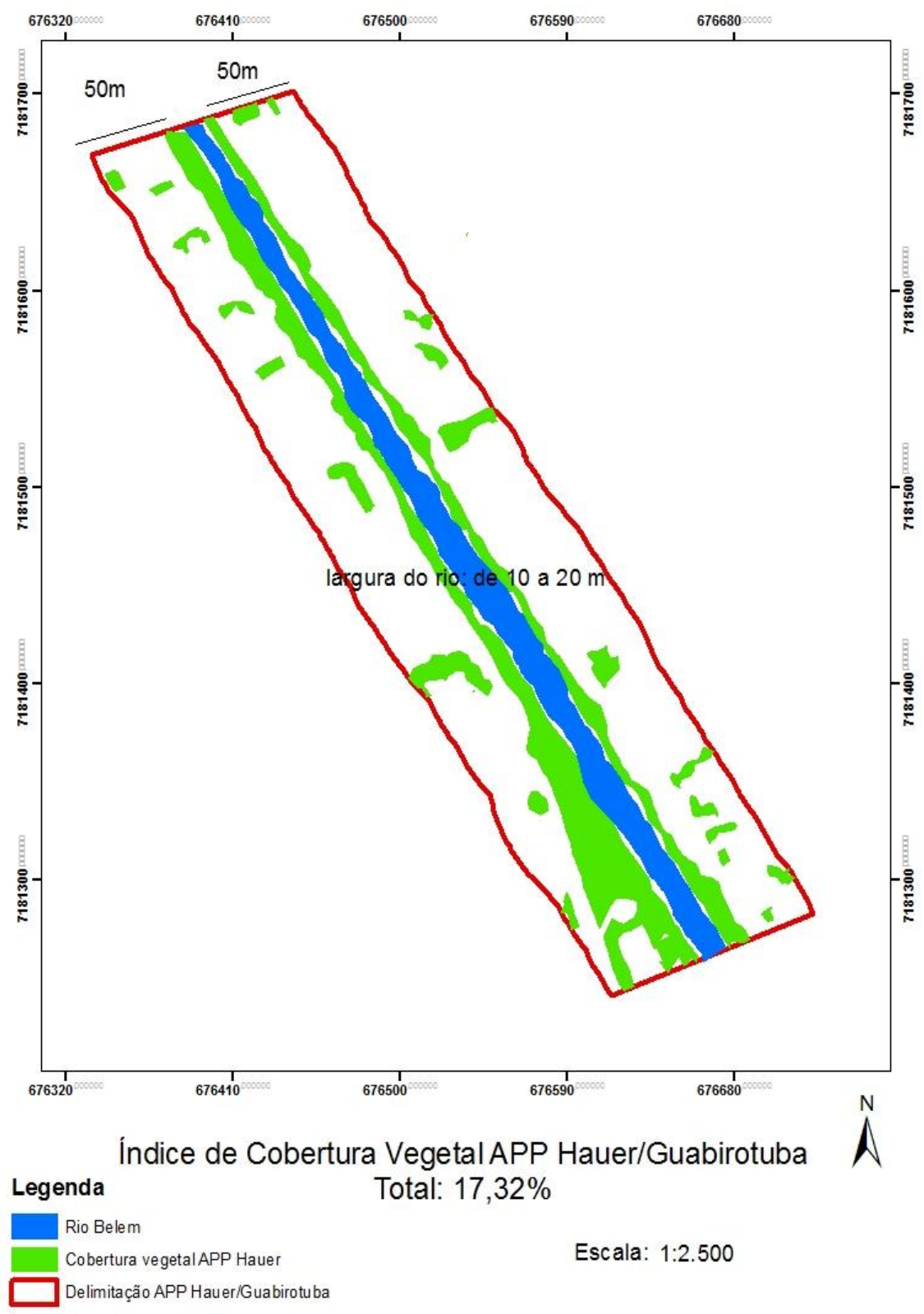

Fonte: Elaborada pelo autor, 2016.

Seu estado de conservação pode ser considerado mínimo, visto a intensa urbanização dentro de sua área e uma pequena área de cobertura vegetal, além de essa ser de vegetação herbácea ou de pequeno porte em uma estreita faixa, além de apesentar problemas de corte de vegetação e erosão em suas margens. 
Ambas as áreas não obedecem, portanto, à legislação do Novo Código Florestal quanto à faixa mínima de preservação de vegetação, além de apresentar graves problemas relacionados à ocupação antrópica.

\section{Conforme Morona,}

o intenso processo de urbanização na bacia do Rio Belém, principalmente, após a área central de Curitiba, em sua direção mais à região sul da cidade, faz com que esse rio se torne cada vez mais degradado, com intensa carga de poluição e pouca cobertura vegetal preservada, além de um intenso processo de urbanização mais ao sul, da bacia hidrográfica. A única área que, teoricamente, ainda se encontra em condições de se elaborar um planejamento ambiental, é delimitada entre as nascentes do Rio Belém até as imediações do Parque São Lourenço (2005, p. 20).

\section{CONFLITOS DE OCUPAÇÃO NAS APPS}

Os conflitos de uso do solo são inúmeros em ambas as áreas, conforme as Figuras 4 e 5.

Figura 4 - conflitos na área de APP no bairro Abranches

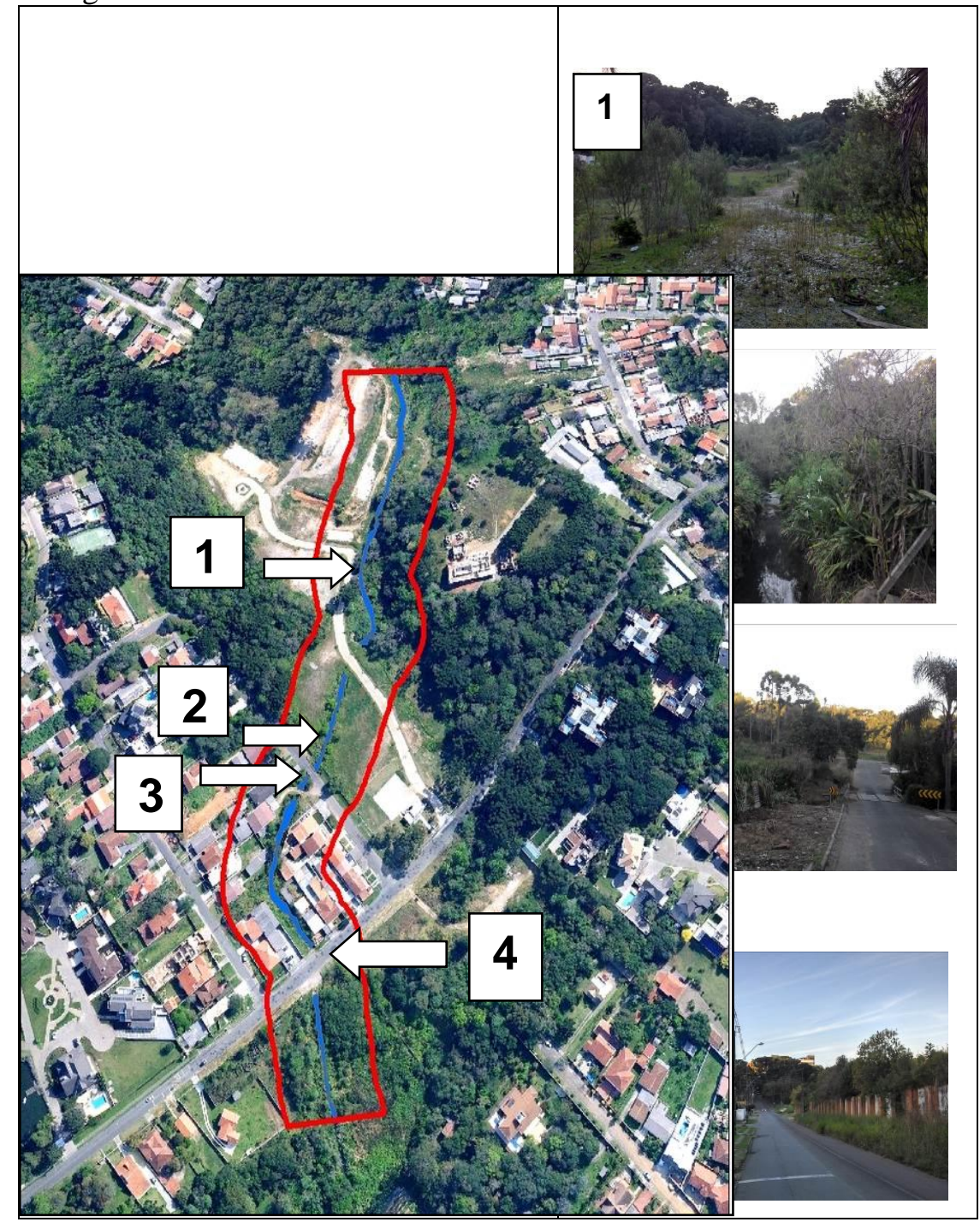


As fotos ilustram respectivamente: 1 - Solo exposto e presença de resíduos de construção civil; 2 - Vegetação herbácea, rasteira e arbustiva. Área pouco vegetada, quanto à vegetação original (Floresta Ombrófila Mista Aluvial); 3 - Caminhos e ruas na área de APP, afetando o curso do Rio, que se situa um trecho canalizado. Rua Adolfo Henrique Kliger; 4 - Área de habitação, muito próxima do Rio Belém, na Rua Reinaldo Recke.

Elaboração: Misael (2016).

Fonte: Google Earth Pro (2016); Misael, 2016.

Figura 5- Conflitos na área de APP, vilas Hauer/Guabirotuba

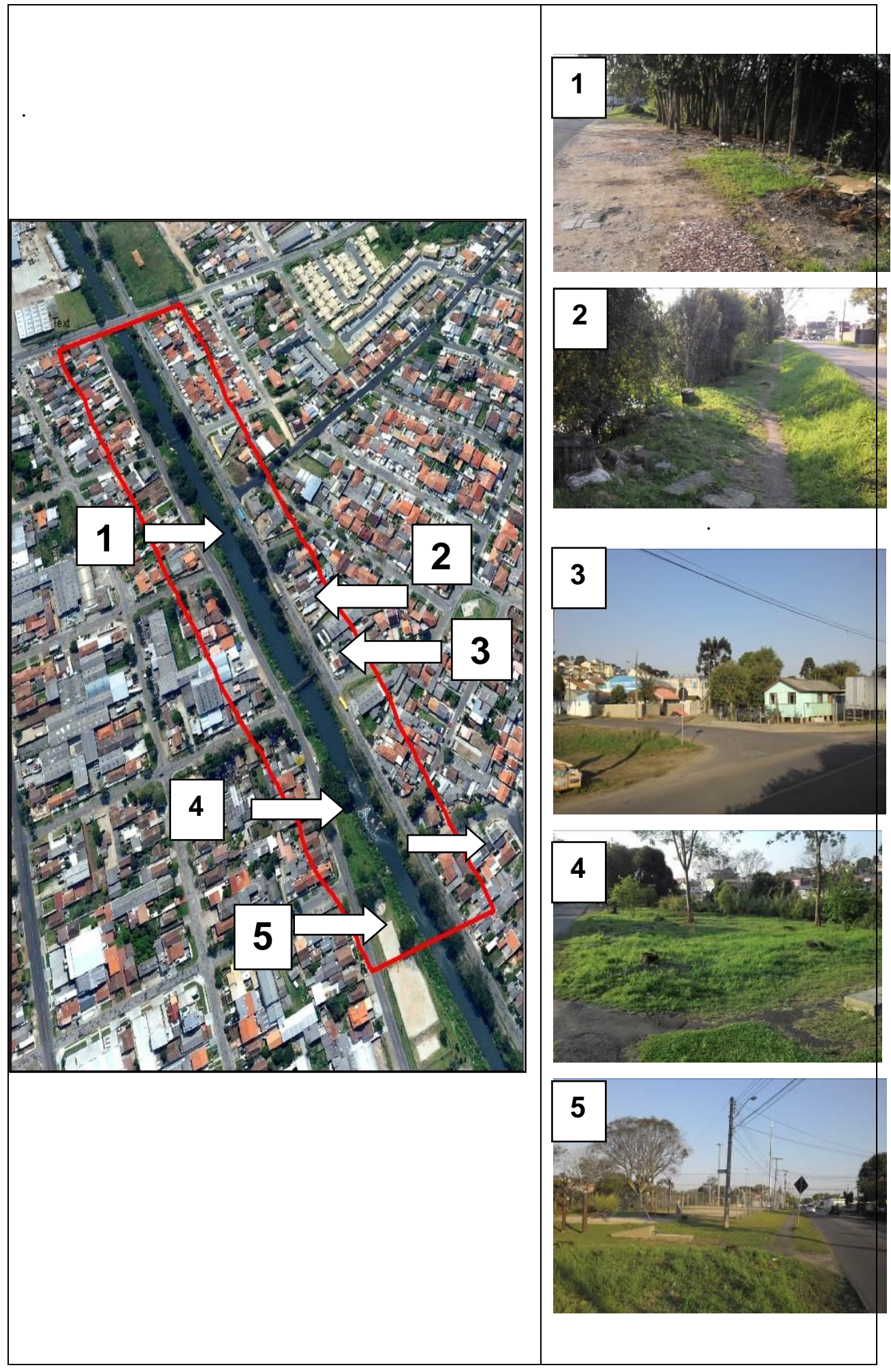


As fotos ilustram respectivamente: 1 - Solos expostos nas margens do rio, na rua Canal Belém. Vila Hauer; 2 Caminhos e ruas, além de vegetação cortada dentro da APP. Rua Canal Belém. Bairro Guabirotuba; 3 - Áreas vegetadas, porém com pouca vegetação em relação à original. Rua Canal Belém, Vila Hauer; 4 - Área de Uso de Lazer. Praça Nair Pereira Queirolo. Rua Canal Belém, Vila Hauer; 5 - Área de grande adensamento habitacional dentro da APP. Bairro Guabirotuba, na rua Canal Belém.

Elaboração: Misael, 2016.

Fonte: Google Earth Pro, 2016; Misael, 2016.

Com relação à quantificação de cada conflito de uso de solo em ambas as áreas, apresenta-se o resultado conforme a tabela 1.

Tabela 1 - Análise quantitativa dos conflitos nas áreas de APPs

\begin{tabular}{|c|c|c|c|c|c|}
\hline & & $\begin{array}{c}\text { APP Abranches } \\
\qquad\left(\mathbf{m}^{2}\right)\end{array}$ & $\begin{array}{c}\text { APP Hauer/ } \\
\text { Guabirotuba } \\
\left(\mathbf{m}^{2}\right)\end{array}$ & $\begin{array}{c}\text { APP Abranches } \\
(\%)\end{array}$ & $\begin{array}{c}\text { APP Hauer/ } \\
\text { Guabirotuba } \\
(\%)\end{array}$ \\
\hline \multirow[t]{6}{*}{ Conflitos } & $\begin{array}{c}\text { Área com } \\
\text { vegetação, } \\
\text { sem ser } \\
\text { vegetação } \\
\text { nativa }\end{array}$ & 14056,66 & 6624 & 48,02 & 9,9 \\
\hline & Solo Exposto & 1951,45 & 654,31 & 6,67 & 0,97 \\
\hline & $\begin{array}{l}\text { Caminhos e } \\
\text { ruas }\end{array}$ & 1789,08 & 8132,18 & 6,11 & 12,15 \\
\hline & $\begin{array}{l}\text { Habitação na } \\
\text { APP }\end{array}$ & 5028,01 & 19728,45 & 17,17 & 29,48 \\
\hline & Uso de lazer & - & 478,33 & - & 0,71 \\
\hline & Total & 29274,77 & 66909,28 & & \\
\hline
\end{tabular}

Fonte: Elaborada pelo autor, 2015.

As duas áreas se diferenciam bem quanto ao tipo de conflito existente. Nota-se que a APP do bairro Abranches possui como maior conflito de uso do solo a pouca vegetação em relação à vegetação original, mesmo essa possuindo um maior índice de cobertura vegetal, o que não levou em conta nesta análise apenas a vegetação nativa, mas sim qualquer vegetação.

Ao se comparar com a área da Vila Hauer, essa possui menos cobertura vegetal, e, consequentemente, menos área com vegetação original.

A diferença maior entre as duas é quando se somam as áreas de habitação e presença de caminhos e ruas (asfaltadas ou não). A área da Vila Hauer/Guabirotuba possui um percentual maior e, consequentemente, maiores problemas que afetam a qualidade ambiental 
local, além de possuir muitos caminhos ou corredores de caminhada, similares a parques lineares, por toda a faixa que deveria ser de preservação da APP.

Quanto ao padrão de habitação também verificado, pode-se concluir que a área do bairro Abranches possui maior poder aquisitivo e é melhor servida de proteção ambiental, no sentido de supressão vegetacional e poluição das águas. Já a área da Vila Hauer/Guabirotuba possui um padrão adensado, com um padrão de moradia inferior ao do bairro Abranches, além do intenso comércio na região. Isso acaba por influenciar na qualidade ambiental local, o que se pode verificar concluindo que o trecho do rio Belém em maior estado de degradação é o da Vila Hauer/Guabirotuba.

A questão da área da ocupação nas APPs do estudo já é um problema de vários anos, dado o tempo de consolidação da área urbana ao longo do rio Belém. Realocar toda a população para poder revitalizar as áreas de APP é algo que poderia se tornar um problema social e cultural, e de forte resistência.

Porém, Moura, em sua análise das ocupações na APP do Rio Cascatinha no bairro Santa Felicidade, afirma que

a vegetação no meio urbano é tão fundamental quanto qualquer outro recurso ou infraestrutura, que possibilita a melhoria da qualidade ambiental. A criação e manutenção de APPs é um meio se assegurar isso; entretanto, há casos em que não se pode simplesmente remover uma série de casas porque elas estão dentro de uma APP, existem pessoas ocupando esses lugares, então, as medidas devem ser planejadas cuidadosamente, inclusive em caso de remoção (2007, p. 20).

Moura cita ainda que:

nesse sentido, uma resolução recente do CONAMA, de n $^{\circ} 369$ de 28 de março de 2006, vem regular a intervenção em APPs para a implantação de obras, planos, atividades ou projetos de utilidade pública ou interesse social, ou para realização de ações consideradas eventuais e de baixo impacto ambiental (2007, p. 20).

Tal resolução tem, segundo o Ministério do Meio Ambiente, o objetivo de possibilitar a regularização das atividades e ocupações já consolidadas e impossibilitar a degradação de novas áreas de preservação através de novas ocupações.

O Novo Código Florestal aborda esses aspectos em seu Art. 8 "A intervenção ou a supressão de vegetação nativa em Área de Preservação Permanente somente ocorrerá nas hipóteses de utilidade pública, de interesse social ou de baixo impacto ambiental previstas nesta Lei”.

E Curitiba, em seu plano diretor, deve contemplar leis de usos do solo, visando à proteção ambiental, seguindo também o Novo Código Florestal, buscando minimizar a 
degradação ambiental urbana, relacionado com a supressão de vegetação, poluição de rios e lagos e problemas de resíduos e esgotos.

Segundo Carvalho,

$$
\begin{aligned}
& \text { projetos de revitalização, renaturalização, restauração, remediação podem contribuir } \\
& \text { para a melhoria da qualidade ambiental de rios urbanos, visto que esses processos } \\
& \text { buscam o reestabelecimento da integridade ecológica de um dado rio, através de } \\
& \text { manejo e recuperação de rios e córregos degradados em áreas urbanas }(2013, p, 19) \text {. }
\end{aligned}
$$

Através das análises, pode-se considerar também que o padrão de habitação e do uso do solo afeta diretamente a qualidade ambiental, e que o ordenamento e planejamento territorial não se dão de forma igualitária na cidade de Curitiba.

\section{CONCLUSÃO}

A ocupação desordenada com a supressão da cobertura vegetal e não preservação das APPs é um problema recorrente na maioria das cidades brasileiras. As áreas analisadas apresentam problemas relevantes quanto à ocupação em área que deveria ser preservada a faixa de vegetação, porém, nas análises, conclui-se que a falta de planejamento urbano no passado aliada ao crescimento desordenado atual e à falta de mecanismos mais rígidos quanto a leis ambientais atuais, bem como à má administração pública, acarretam em consequências na qualidade ambiental urbana.

Porém, muitas vezes, a legislação se apresenta de forma contraditória, por exemplo, ao dar direito de um ambiente ecologicamente equilibrado e direito à propriedade, mas esse proprietário que possui um lote acaba não preservando a vegetação na APP. Há também o problema de que muitas leis municipais e federais não se combinam, ou uma acaba por anular a outra, e, muitas vezes, a lei municipal acaba sendo a privilegiada. Isso quando se cumpre alguma Lei Ambiental.

O planejamento ambiental e urbano deve contemplar todas as regiões da cidade de forma igualitária. O que, muitas vezes, ocorre é que nem sempre isso se dá dessa forma, sendo que uma área com melhor padrão de ocupação urbana (mesmo em área de APP) ainda possui alguns privilégios quanto a paisagismo e menos degradação, podendo repercutir na qualidade de vida dos habitantes nessa região. E, com este estudo, pode-se verificar essa problemática.

Sugere-se também que, além da preservação das faixas mínimas da vegetação ciliar, se trabalhe intensivamente na minimização de lançamento de esgotos não tratados ou resíduos nas águas dos rios urbanos, aliado a um trabalho de educação ambiental, podendo, dessa 
forma, melhorar a qualidade ambiental urbana em relação à qualidade das águas de nossos rios urbanos.

\section{REFERÊNCIAS}

BARBOUR, M. T.; STRIBLING, J. B. A workshop on a technique for assessing stream habitat structure for nonpoint source evaluation. In: Anais do Watershed 96', S 57 01/665670. Disponível em: <http://www.epa.gov/owow>. Acesso em: 10 ago. 2016.

BOLLMANN, Harry Alberto; EDWIGES, Thiago. Avaliação da qualidade das águas do Rio Belém, Curitiba - PR, com o emprego de indicadores quantitativos e perceptivos. Engenharia sanitária ambiental, Curitiba, v. 13, n. 4, p. 443-452, dez. 2008.

BRASIL. Lei n. 12.651, de 25 de maio de 2012. Código Florestal. Disponível em: <http://www.planalto.gov.br/ccivil_03/_ato2011-2014/2012/lei/112651.htm>. Acesso em: 5 de ago. 2016.

CARVALHO, Juliana Wilse Landolfi Teixeira de. Perspectiva de renaturalização de rios urbanos: estudo de caso na micro-bacia hidrográfica Córrego do Aviário. 2013. 73 f. Monografia (Graduação em Bacharelado em Geografia) - Curso de Geografia, Departamento de Geografia, Universidade Federal do Paraná, Curitiba, 2013.

ESTÊVEZ, Laura Freire. Relatórios Ambientais Prévios (RAPs) realizados em Curitiba (PR): uma análise com base nos princípios do planejamento da paisagem. 2014. $166 \mathrm{f}$. Tese (Doutorado em Geografia) - Curso de Programa de Pós-Graduação em Geografia, Setor de Ciências da Terra, Universidade Federal do Paraná, Curitiba, 2014.

FENDRICH, Roberto. Diagnóstico dos recursos hídricos da bacia hidrográfica urbana do rio Belém. Curitiba: Assembleia Legislativa do Estado do Paraná, 2002.

FORTUNATO, Rafaela Antunes. Subsídios à prevenção e controle de inundações urbanas: bacia hidrográfica do rio Belém, município de Curitiba-PR. 2006. 237 f. Dissertação (Mestrado em Engenharia Civil) - Curso de Construção Civil, Universidade Federal do Paraná, Curitiba, 2006. Disponível em: <http://www.ppgcc.ufpr.br/dissertacoes/d0071.pdf>. Acesso em: 20 ago. 2016.

GARCIA, Yara Manfrin. Conflitos de uso do solo em APPs na bacia hidrográfica do córrego barra seca (Pederneiras/SP) em função da legislação ambiental. 2014. $109 \mathrm{f}$. Dissertação (Mestrado em Agronomia) - Curso de Agronomia, Universidade Paulista Julio de Mesquita Filho - Unesp, Botucatu, 2014. Disponível em: <www.pg.fca.unesp.br/Teses/PDFs/Arq1089.pdf >. Acesso em: 15 ago. 2015.

IPPUC, Instituto de Pesquisa e Planejamento Urbano de Curitiba. $2^{\mathbf{a}}$ Conferência Municipal da Cidade de Curitiba. Curitiba: IPPUC / Universidade da Cidade, 2005.

MACHADO, P.A.L. Direito Ambiental Brasileiro. 10. ed., rev., ampl. e atual. São Paulo: Malheiros, 2002.

MAURO, C. A. Laudos Periciais e em Depredações Ambientais. Rio Claro: Laboratório de Planejamento Municipal - DPR IGCE-UNESP, 1997.

MOURA, Angelita Rolim de; NUCCI, João Carlos. Conservação em áreas de preservação permanente no bairro de santa felicidade - Curitiba - Paraná. In: XII Simpósio Brasileiro de Geografia Física Aplicada - Natureza, Geotecnologias, Ética e Gestão do Território, 12, 2007, Natal. Anais... Natal: Natal, 2007. v. 1, p. 1-15.

MORONA, R. E. C. Avaliação da qualidade de vida da população residente na Bacia Hidrográfica do Rio Belém, Curitiba - PR, no trecho entre a nascente e o Parque São 
Lourenço, Curitiba, 2005. Disponível em: $<$ http://www.pucpr.br/template.php?codredir=440\&\&codigo=1>. Acesso em: 10 jul. 2016. MOTA, Suetônio. Urbanização e Meio Ambiente. 3. ed. Rio de Janeiro: ABES, 2003.

NUCCI, J. C.; CAVALHEIRO, F. Cobertura vegetal em áreas urbanas - conceito e método. GEOUSP 6, São Paulo: Depto. de Geografia/USP, p. 29-36, 1999.

NUCCI, J. C. Qualidade ambiental e adensamento urbano. São Paulo: Humanitas/FAPESP, 2001.

Revitalização do rio Cheonggyecheon em Seul, na Coreia do Sul. Disponível em: <http://www.facool.com.br/noticia/view/3221>. Acesso em: 15 set. 2016. 